\title{
Biochemical basis of permethrin resistance in Anopheles arabiensis from Lower Moshi, north-eastern Tanzania
}

\author{
Johnson Matowo ${ }^{1,2^{*}}$, Manisha A Kulkarni ${ }^{3}$, Franklin W Mosha ${ }^{1,2}$, Richard M Oxborough ${ }^{1,2,4}$, Jovin A Kitau ${ }^{1,2}$, \\ Filemoni Tenu ${ }^{1,5}$, Mark Rowland ${ }^{1,4}$
}

\begin{abstract}
Background: Development of resistance to different classes of insecticides is a potential threat to malaria control. With the increasing coverage of long-lasting insecticide-treated nets in Tanzania, the continued monitoring of resistance in vector populations is crucial. It may facilitate the development of novel strategies to prevent or minimize the spread of resistance. In this study, metabolic-based mechanisms conferring permethrin (pyrethroid) resistance were investigated in Anopheles arabiensis of Lower Moshi, Kilimanjaro region of north-eastern Tanzania.

Methods: WHO susceptibility test kits were used to detect resistance to permethrin in An. arabiensis. The levels and mechanisms of permethrin resistance were determined using CDC bottle bioassays and microplate (biochemical) assays. In bottle bioassays, piperonyl butoxide (PBO) and s,s,s-tributyl phosphorotrithioate (DEF) were used as synergists to inhibit mixed function oxidases and non-specific esterases respectively. Biochemical assays were carried out in individual mosquitoes to detect any increase in the activity of enzymes typically involved in insecticide metabolism (mixed function oxidases, $\alpha$ - and $\beta$-esterases).
\end{abstract}

Results: Anopheles arabiensis from the study area was found to be partially resistant to permethrin, giving only $87 \%$ mortality in $\mathrm{WHO}$ test kits. Resistance ratios at $\mathrm{KT}_{50}$ and $\mathrm{KT}_{95}$ were 4.0 and 4.3 respectively. The permethrin resistance was partially synergized by DEF and by PBO when these were mixed with permethrin in bottle bioassays and was fully synergized when DEF and PBO were used together. The levels of oxidase and $\beta$-esterase activity were significantly higher in An. arabiensis from Lower Moshi than in the laboratory susceptible strain. There was no difference in $\alpha$-esterase activity between the two strains.

Conclusion: Elevated levels of mixed function oxidases and $\beta$-esterases play a role in detoxification of permethrin in the resistant An. arabiensis population of Lower Moshi.

\section{Background}

Resistance to pyrethroids and other insecticides is an important threat to the control of malaria in Africa [1-3]. Early detection of insecticide resistance enables more rational selection of insecticides. In recent years, Anopheline mosquitoes in many parts of Africa have become resistant to pyrethroids, partly in response to agricultural application or run off of insecticides into mosquito breeding sites [2,4-6], but increasingly in response to selection pressure resulting from the scaling up of longlasting insecticide-treated nets and indoor residual

\footnotetext{
* Correspondence: johntowo@yahoo.com

${ }^{1}$ Pan-African Malaria Vector Research Consortium www.pamverc.org
}

spraying as malaria prevention tools [3,7-11]. Development of resistance may necessitate switching to an alternative class of insecticide to enable resumption of control [3]. Early detection of resistance facilitates more rational selection of insecticides or may enable timely introduction of resistance management strategies [12].

There are two broad mechanisms by which insect pests develop resistance to insecticides. They may produce increased quantities of enzymes, which either metabolize the insecticide or sequestrate the molecules so they cannot function. The second mechanism involves mutation of the insecticide target-site. This effectively blocks the action of the insecticide. Both 
types of mechanism have been studied in various species of insects [12-16].

Levels of insecticide resistance in field populations of vectors have been shown to vary over relatively small geographical areas and over different seasons [5,17]. In Africa, the major foci of pyrethroid resistance are found in the western and central regions, especially in cotton growing areas where pyrethroids have been applied intensively against cotton pests [2]. In Anopheles gambiae populations of these areas, reduced target site sensitivity arising from a single point mutation in the sodium channel gene $(k d r)$ has been implicated as the predominant mode of resistance [16], although increased levels of detoxifying enzymes may also play a role [4]. An increase in permethrin tolerance in $A n$. gambiae in Kenya due to localized use of ITNs has been associated with both target site insensitivity and elevated levels of detoxifying mixed function oxidases (MFOs) [18]. In South Africa, Anopheles funestus developed pyrethroid resistance after recurrent campaigns of indoor residual spraying with deltamethrin [3]. Detection of the West African $k d r$ mutation at low frequency in An. arabiensis in Lower Moshi, north-eastern Tanzania [19] and the West African $k d r$ mutation in An. gambiae in Uganda [20] suggests the $k d r$ gene has spread across the African continent.

The standard method for detecting resistance in populations of mosquito vectors is the WHO susceptibility test [21]. Application of a discriminating concentration that distinguishes susceptible from resistant mosquitoes allows accurate detection of resistance when the gene is dominant. But when resistance is recessive or present at low frequency discriminating-dose tests based on mortality may lack the necessary precision. In such situations, the use of knockdown time - expressed as the time taken for $50 \%$ of individuals to be knocked down may prove a more sensitive indicator of resistance [22]. Additional information on resistance mechanisms can be derived from use of synergists, chemicals that inhibit the enzymes responsible for insecticide metabolism [9,12-14,23]. By combining synergist with insecticide in bioassay tests the resistant mosquitoes will return to apparent susceptibility if the inhibited enzyme is responsible for resistance [23]. Biochemical assays have been developed that measure enhanced levels of detoxification enzymes responsible for resistance. These may be performed on individual mosquitoes allowing more sensitive detection of resistance [24-26]. The aim of this study was to investigate the biochemical mechanisms of permethrin resistance in field populations of $A n$. arabiensis from Lower Moshi in Kilimanjaro region of north-eastern Tanzania. In this irrigated rice growing area, $A n$. arabiensis is the predominant vector of malaria [27]. Preliminary studies suggest an absence of $k d r$-based mechanisms [19] while an oxidase-based mechanism may be present [28]. Bioassay and biochemical assays were used to determine the contributions of both mixed function oxidases and non-specific esterases to the observed permethrin resistance.

\section{Methods}

\section{Study area and mosquito collection sites}

The study was carried out on mosquitoes from Lower Moshi, an intensive rice-irrigation area, $37^{\circ} 20^{\prime} \mathrm{E} 3^{\circ} 21^{\prime} \mathrm{S}$ and 700 meters altitude, south of Mount Kilimanjaro in north-eastern Tanzania. Most of the population in the area is engaged in agriculture. Two rivers, the Njoro and the Rau provide water for irrigation. There are two growing seasons, the main one from June to October and the second one involving sporadic cultivation of rice from September to February. Anopheles arabiensis adults were collected during January-April 2007 from the villages of Mabogini, Rau-Kati, and Chekereni.

\section{Mosquito strains}

The two strains used in this study were $A n$. arabiensis Dondotha, a laboratory insecticide susceptible strain, and $A n$. arabiensis wild, a field strain from Lower Moshi, resistant to permethrin, established from collections of indoor resting adult mosquitoes from animal houses. The mosquitoes were transferred to the insectary and females induced to lay eggs. The F1 progeny was divided into two sub samples: one sub sample was stored at $-80^{\circ} \mathrm{C}$ for biochemical analysis while the other was used for insecticide and synergist bioassays.

\section{Diagnostic resistance tests}

Diagnostic tests were conducted on adult An. arabiensis using WHO susceptibility test kits [29]. Batches of 25 blood-fed mosquitoes taken directly from field collections were exposed to $0.75 \%$ permethrin test papers according to WHO procedures with the cylinder placed in a vertical position [21]. Knockdown was recorded every ten minutes during the 1 hour exposure. At the end of the exposure period, mosquitoes were transferred to recovery tubes and provided with glucose solution, held for 24 hours after which mortality was recorded. Four test batches (100 mosquitoes) and one control (25 mosquitoes) were tested during each test run which was replicated ten times; hence 1000 wild females were tested for permethrin resistance status. Tests were carried out in parallel on blood-fed insecticide-susceptible adults of the Dondotha stain of An. arabiensis

\section{Synergy tests}

Bottle bioassay calibration was conducted to determine appropriate concentrations of insecticide and synergist. Glass bottles of $250 \mathrm{ml}$ capacity were coated with three 
concentrations of permethrin $(12.5,25$ or $50 \mu \mathrm{g}$ per bottle) according to the method of Brogdon and McAllister [23] and tested against the susceptible strain for 1-hour to determine the baseline response to permethrin. Ten replicates of ten mosquitoes were tested against each concentration for one hour during which knockdown was recorded at 5 min intervals. The ideal test concentration of insecticide is the lowest one that gives a timemortality response from 0 to $100 \%$ mortality over a convenient test period [23]. To verify that the concentrations of synergist were below toxic levels, a series of concentrations of s,s,s-tributyl phosphorotrithioate DEF (range 62.5-250 $\mu \mathrm{g}$ per bottle) and piperonyl butoxide PBO (range 100-400 $\mu \mathrm{g}$ per bottle) were tested against the susceptible strain for $60 \mathrm{~min}$.

Synergy tests were conducted on adult progeny of wild An. arabiensis from Lower Moshi and on the laboratory susceptible strain. The glass bottles were coated with permethrin with or without a synergist as described by Brogdon et al [23]. PBO, an inhibitor of mixed function oxidases, and DEF, an inhibitor of non-specific esterases, were the synergists used. Four treatments were compared during each test run: permethrin alone, permethrin plus DEF, permethrin plus $\mathrm{PBO}$ or permethrin plus $\mathrm{PBO}$ and DEF together (plus positive and negative controls). Ten non-blood-fed females, three- to five-day old were used in each replicate, and each treatment was tested ten times. Knockdown was recorded at 5-minute intervals for 60 minutes. Mosquitoes were then transferred to holding cups, supplied with glucose solution and mortality recorded after 24 hours.

\section{Biochemical assays}

Biochemical assays were used to quantify the levels of mixed function oxidase and non-specific esterase activity in individual mosquitoes. Individual 2-5 day old $A n$. arabiensis adults, reared under insecticide-free conditions and stored at $-80^{\circ} \mathrm{C}$, were homogenized manually in sodium phosphate buffer ( $\mathrm{pH} 7.2$ ) inside a $1.5 \mathrm{ml}$ eppendorf tubes. For the oxidase assays individuals were homogenized in $100 \mu \mathrm{l}$ of $0.0625 \mathrm{M}$ sodium phosphate buffer ( $\mathrm{pH}$ 7.2), which was then diluted by adding 1,400 $\mu \mathrm{l}$ of the sodium phosphate buffer. For esterase assays, individuals were homogenized in $20 \mu \mathrm{l}$ of $0.02 \mathrm{M}$ sodium phosphate buffer ( $\mathrm{pH}$ 7.2) to which $100 \mu \mathrm{l}$ of distilled water was added. A hundred microlitres of sodium phosphate buffer $\mathrm{pH} 7.2$ was added to the aliquots of mosquito homogenates and $200 \mu \mathrm{g}$ of 3, 3, 5', 5'-tetramethhyl benzidine (TMBZ) solution ( $0.01 \mathrm{~g}$ of $3,3,5^{\prime}$, $5^{\prime}$-tetramethhyl benzidine in $5 \mathrm{ml}$ of absolute methanol, mixed with $0.25 \mathrm{M}$ sodium acetate buffer $\mathrm{pH}$ 5.0) was added. Twenty-five microlitres of $3 \%$ hydrogen peroxide was added and the mixture was left for two hours at room temperature. The oxidase enzyme activity was then read at $630 \mathrm{~nm}$. For the esterase assays $20 \mu \mathrm{l}$ of $\alpha$ naphthyl acetate solution $(1 \mathrm{ml}$ of $30 \mathrm{mM} \alpha$-naphthyl acetate in acetone in $99 \mathrm{ml}$ of $0.02 \mathrm{M}$ phosphate buffer $\mathrm{pH}$ 7.2) and $200 \mu \mathrm{g} \beta$-naphthyl acetate solution (prepared as for $\alpha$-naphthyl acetate solution) were added to replicates of mosquito homogenates. The enzyme reaction was run for two minutes at room temperature before the addition of $50 \mu \mathrm{l}$ of Fast blue stain solution. The absorbance value for each well was determined at $570 \mathrm{~nm}$.

\section{Statistical analysis}

Mortality in WHO resistance tests was corrected for control mortality using Abbott's formula [30]. $\mathrm{KT}_{50}$ and $\mathrm{KT}_{95}$ values in the bottle bioassays and resistance ratios between wild and susceptible strains were estimated using probit analysis (Polo Plus 1.0, LeOra Software). Enzyme expression levels between strains were compared using t-tests.

\section{Results}

\section{WHO resistance tests}

Percentage mortality to permethrin in susceptibility tests conducted on wild females from the villages of Mabogini, Rau Kati, and Chekereni ranged from $75.5 \%$ to $96.1 \%$ and showed an average of $87 \%$ mortality (corrected for control). Mortality of the laboratory susceptible strain was $100 \%$. Figure 1 shows mean percentage knockdown at different time intervals.

Knockdown took considerably longer in tests on the wild strain: the time for $50 \%$ to be knocked down took $28 \mathrm{~min}$ in the wild strain but took less than $7 \mathrm{~min}$ in the susceptible strain. The resistance ratios at $\mathrm{KT}_{50}$ and $\mathrm{KT}_{95}$ were 4.0 and 4.3 respectively (Table 1 ).

\section{Bottle bioassays and synergy tests}

The best-fit straight line $\left(R^{2}=0.91\right)$ was obtained with $12.5 \mu \mathrm{g} / \mathrm{bottle}$ permethrin. The highest concentration of synergist that produced no lethal effect was $200 \mu \mathrm{g}$ PBO per bottle and $125 \mu \mathrm{g}$ DEF per bottle. These concentrations of insecticide and synergist were used in subsequent synergy tests. Following exposure to permethrin for 60 minutes, the \% mortality rate of 3-5 day old female mosquitoes of An. arabiensis wild was consistently lower than that observed for the susceptible strain (Table 2). Knockdown time at $\mathrm{KT}_{50}$ and $\mathrm{KT}_{95}$ was higher in the wild than in the susceptible strain and the resistance ratios were 2.7 folds lower in the bottle bioassay than in the WHO resistance tests.

When F1 An. arabiensis mosquitoes were exposed to permethrin plus $\mathrm{PBO}$ or DEF the \% knockdown was much higher than when exposed to permethrin alone (Figure 2). Permethrin plus PBO consistently recorded higher \% knockdown than permethrin plus $\mathrm{PBO}$ and 


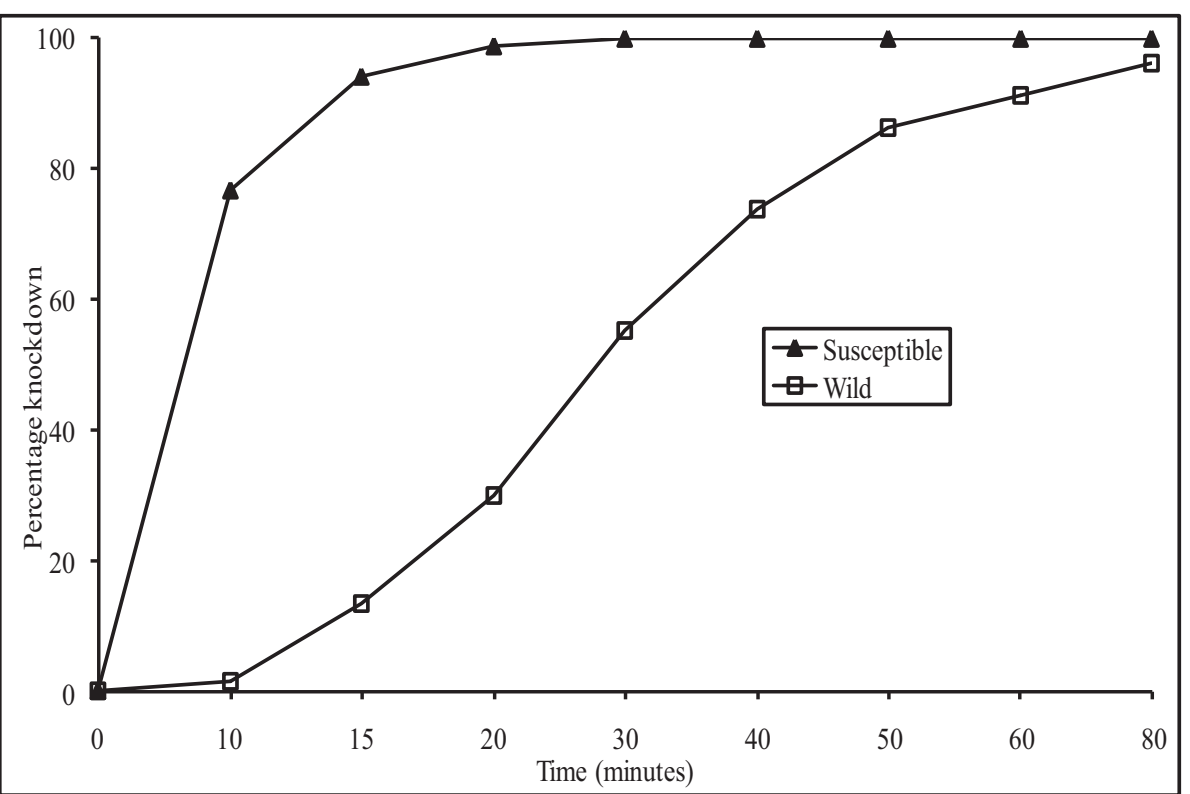

Figure 1 Percentage knockdown over time for F1 generation of wild mosquitoes and susceptible strain. Ten replicates were run for each strain ( $n=1069$ for F1 Anopheles arabiensis (susceptible), $n=1011$ for F1 Anopheles arabiensis (wild).

DEF in replicates. The synergy ratio was relatively higher when permethrin was synergized by $\mathrm{PBO}$ than when it was synergized by either DEF or both $\mathrm{PBO}$ and DEF (Table 3).

\section{Microplate assays of esterase and oxidase activity}

The means and confidence intervals for the optical density values for $\alpha$-esterases, $\beta$-esterases and mixed function oxidases are shown in table 4 . The mean levels of mixed function oxidase and beta $\beta$-esterase activity were significantly higher for An. arabiensis wild than for the susceptible strain. However, the mean levels of $\alpha$-esterase activity were not significantly different between wild and susceptible strains. Figures 3,4 and 5 show the distribution of MFO, $\alpha$-esterase and $\beta$-esterase activity respectively. The OD cut off points that discriminate between susceptible and wild strains were 0.165 for MFOs and 0.45 for $\beta$-esterases; the proportion of wild individuals scoring above these thresholds were $50 \%$ $(15 / 30)$ for MFOs and 44\% (17/39) for $\beta$-esterases. These biochemical proportions are higher than the proportion of mosquitoes that showed phenotypic resistance in $\mathrm{WHO}$ and bottle bioassay resistance tests which suggests that a combination of elevated MFO and elevated esterase activity might be required to give rise to phenotypic resistance.

\section{Discussion}

The study showed that a low frequency of permethrin resistance mediated by MFOs and $\beta$-esterases is present in An. arabiensis, the predominant malaria vector of Lower Moshi. The permethrin resistance is probably caused by the agricultural use of insecticides, especially in the rice fields, as permethrin-treated nets are not widely used in Lower Moshi for protection against mosquitoes. In Kenya, the localized use of permethrin-impregnated nets in Kisumu did increase the permethrin tolerance of the local population of An. gambiae sensu stricto [18].

However, there was no evidence that it reduced the efficacy of permethrin-impregnated nets as a malaria control measure [31]. The present frequency of resistance in Lower Moshi appears to not impair the effectiveness of permethrin treated nets. A recent field trial in Moshi shows that while such treated nets kill

Table 1 Susceptibility tests with permethrin

\begin{tabular}{lcccc}
\hline & \multicolumn{2}{c}{ Knockdown time (minutes) for permethrin } & \multicolumn{2}{c}{ \%24 $\mathbf{h}$ mortality [Corrected for control] } \\
\cline { 2 - 5 } & $\mathbf{K T}_{\mathbf{5 0}} \mathbf{( 9 5 \% ~ C . I )}$ & $\mathbf{K T}_{\mathbf{9 5}}$ (95\% C.I) & Permethrin & DDT \\
\hline Susceptible & $7(5-8)$ & $16(15-18)$ & $100[100]$ & $100[100]$ \\
Wild & $28(27-29)$ & $69(65-74)$ & $88[87]$ & $100[100]$ \\
\hline Resistance ratios & 4.0 & 4.3 & & \\
\hline
\end{tabular}


Table 2 Bottle bioassay tests with permethrin

\begin{tabular}{lccc}
\hline & \multicolumn{2}{c}{ Knockdown time (minutes) } & \multirow{2}{*}{$\%$ mortality } \\
\cline { 2 - 3 } & $\mathbf{K T}_{\mathbf{5 0}}$ (95\% C.I) & $\mathbf{K T}_{\mathbf{9 5}}$ (95\% C.I) & \\
\hline Susceptible & $17(15-19)$ & $30(27-35)$ & 95 \\
Wild & $26(24-27)$ & $49(45-54)$ & 78 \\
\hline Resistance ratios & 1.5 & 1.6 & \\
\hline
\end{tabular}

The $\mathrm{p}$-value for $\mathrm{KT}_{50}$ and $\mathrm{KT}_{95}<0.001$

relatively few host-seeking An. arabiensis that enter local houses the nets continue to provide personal protection through the strong excito-repellent activity of permethrin [32]. Permethrin-treated nets in the form of the Olyset LLIN are now being scaled up in Tanzania as national malaria control policy and if the increased coverage selects further for permethrin resistance the effectiveness of the LLIN strategy may ultimately be undermined. Stump et al [33] recently reported pyrethroid resistance in the form of $k d r$ from an area of long-term ITN use in western Kenya. Applying SSOPELISA method, Kulkarni et al [19] reported $k d r$ (western variant) at low frequency in An. arabiensis just a few kilometers from the present study area. Only 2 out of 642 mosquitoes $(0.3 \%)$ appeared to carry $k d r$ mutation and only in heterozygous genotype. The $k d r$ mechanism results from mutations in the voltage-gated sodium channels, the target-site for DDT and pyrethroids. Furthermore, there is no DDT resistance in the study area as recorded in Table 1 . The absence of DDT resistance and the presence of permethrin resistance suggest insecticide detoxification by enzymes to be the more important mechanism for permethrin resistance in Lower Moshi. At the moment $k d r$ is too rare to be
Table 3 Synergy tests with wild mosquitoes

\begin{tabular}{lllll}
\hline Treatment & \multicolumn{2}{l}{$\begin{array}{l}\text { Knockdown time } \\
\text { (minutes) }\end{array}$} & \multicolumn{3}{l}{$\begin{array}{l}\text { Synergy } \\
\text { ratios }\end{array}$} \\
\cline { 2 - 6 } & $\left.\mathbf{( K T}_{\mathbf{5 0}}\right)$ & $\left.\mathbf{( K T}_{\mathbf{9 5}}\right)$ & $\left.\mathbf{K T}_{\mathbf{5 0}}\right)$ & $\left.\mathbf{( K T}_{\mathbf{9 5}}\right)$ \\
\hline Permethrin alone & $26(24-27)$ & $49(45-54)$ & & \\
Permethrin + PBO & $15(13-16)$ & $23(21-25)$ & 1.7 & 2.1 \\
Permethrin + DEF & $20(18-22)$ & $33(30-37)$ & 1.3 & 1.5 \\
\hline Permethrin + PBO + DEF & $18(16-20)$ & $28(26-32)$ & 1.4 & 1.8 \\
\hline
\end{tabular}

The p-value for $\mathrm{KT}_{50}$ and $\mathrm{KT}_{95}<0.001$

important but further selection of combined metabolic and site insensitivity resistance by wider use of LLINs might constitute a grave threat.

Mixed function oxidases (MFOs) and non-specific esterases (NSEs) are commonly involved in the detoxification of permethrin [34-36]. Elevated levels of such enzymes are known to enhance permethrin resistance [24]. Exposure of An. arabiensis (wild) to permethrin plus DEF or PBO synergists inhibited non-specific esterase and oxidase activities and led to higher mortality rates than exposure to permethrin alone. This indicates involvement of both oxidases and esterases in conferring permethrin resistance. Exposure to permethrin with PBO and DEF together resulted in an exposure time/ mortality curve equivalent to that of the susceptible strain of An. arabiensis exposed to permethrin alone, with $\mathrm{KT}_{50}$ value that is within the $\mathrm{KT}_{50} 95 \% \mathrm{CI}$ of the susceptible strain. This implies total inhibition of permethrin resistance in the wild strain.

Higher mortality produced in An. arabiensis exposed to permethrin plus $\mathrm{PBO}$ relative to the susceptible strain exposed to permethrin could be due to significant

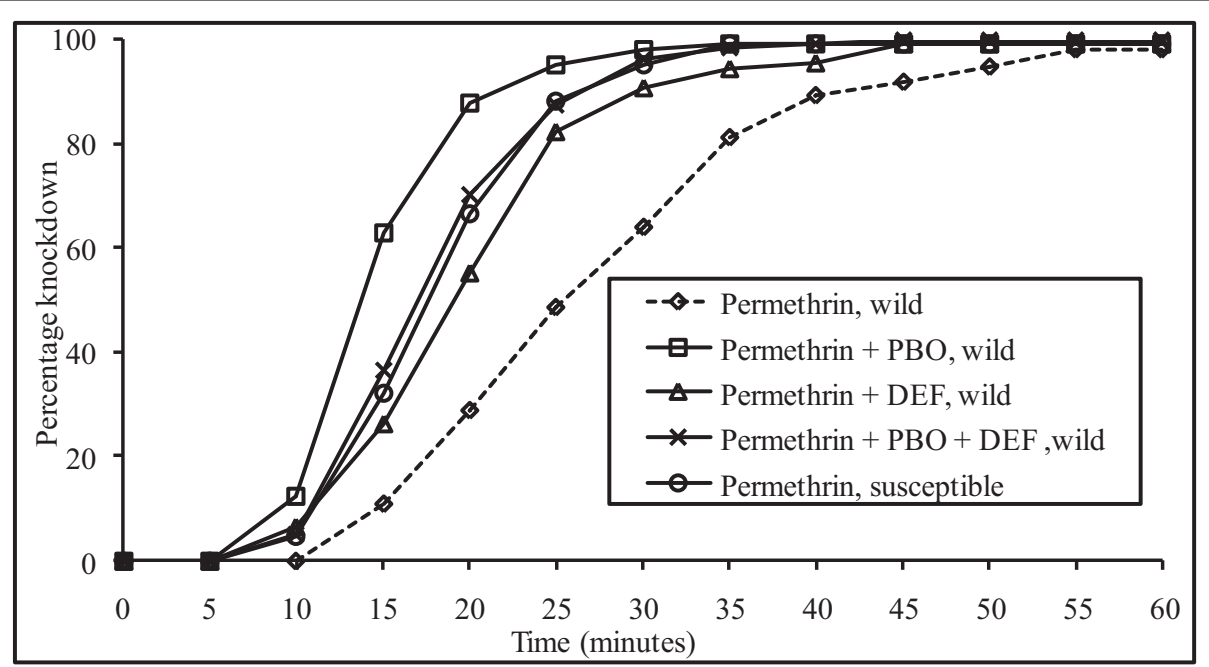

Figure 2 Mortality over time for F1 generation wild mosquitoes exposed to permethrin alone, permethrin $+\mathrm{PBO}$, permethrin $+\mathrm{DEF}$, permethrin + PBO + DEF (plus permethrin test of susceptible mosquito strain). Each curve is represented by data from ten replicates ( $n \sim 100$ mosquitoes). 
Table 4 Microtitre plate assays of enzyme activity

\begin{tabular}{llll}
\hline & \multicolumn{3}{l}{ Optical Density values: Mean $(\mathbf{C l})$} \\
\cline { 2 - 4 } & $\begin{array}{l}\boldsymbol{\alpha} \text { - esterase } \\
\mathbf{( n = 3 9 )}\end{array}$ & $\begin{array}{l}\boldsymbol{\beta} \text { - esterase } \\
(\mathbf{n}=\mathbf{2 2})\end{array}$ & $\begin{array}{l}\text { Oxidase } \\
(\mathbf{n}=\mathbf{3 0})\end{array}$ \\
\hline Susceptible & $0.79(0.52-1.05)$ & $0.26(0.23-0.30)$ & $0.12(0.11-0.13)$ \\
Wild & $0.84(0.58-1.11)$ & $0.48(0.36-0.60)$ & $0.17(0.20-0.14)$ \\
\hline Difference & $-0.05^{*}$ & $-0.22^{* *}$ & $-0.06^{* *}$ \\
& $(-0.45,0.34)$ & $(-0.35,-0.08)$ & $(-0.08,-0.03)$ \\
\hline
\end{tabular}

increase in the cuticular penetration rate of permethrin. It suggests that the synergist might have caused synergism by an acceleration of permethrin across the cuticle on addition to increased permethrin detoxification in the resistant wild mosquito strain. According to Sun and Johnson [37], some synergists cause synergism solely by an acceleration of insecticide across the cuticle (quasi-synergism). The study by Kennaugh et al [38] shows no evidence for increased permethrin detoxification in the resistant strain of Helicoverpa armigera (cotton bollworm) although permethrin resistance could be eliminated with PBO. This suggests accelerated permethrin penetration through the cuticle as a possible mechanism for that synergism. In 1995, Gunning et al [39] reported an increased rate of esfenvalerate penetration in the presence of $\mathrm{PBO}$ in Helicoverpa armigera. The lower mortality observed when An. arabiensis was exposed to permethrin with $\mathrm{PBO}$ and DEF together compared to when exposed to permethrin plus $\mathrm{PBO}$ is probably due to antagonistic effect of DEF to $\mathrm{PBO}$ on cuticular penetration of the permethrin. In this case, DEF might have reduced penetration of the permethrin, hence reducing the time for its detoxification. It could also be due to esterase inhibition by PBO resulting in the loss of esterase-mediated sequestration of the permethrin. The new assay devised by Khot et al [40] reveals the blockade of esterases by PBO. This could not be the case in this mosquito population since the observed mortality when permethrin was mixed with $\mathrm{PBO}$ alone is significantly different from the observed mortality when permethin was mixed with both $\mathrm{PBO}$ and DEF.

Elevation of one or more broad substrate spectrum esterase is a common mechanism of insecticide resistance in Culex species [41]. Although less common in Anopheles, elevated esterases have been documented in pyrethroid-resistant An. gambiae from Kenya $[14,15]$. In the present study, the association of elevated mixed function oxidases and non-specific esterases was confirmed biochemically using oxidase and esterase detection assays. The proportion of $A n$. arabiensis wild with enzyme levels higher than that for the susceptible strain did not equate with the phenotypic expression of resistance in WHO test kits or bottle bioassays. This may mean that elevated MFOs and esterases must occur together to give rise to phenotypic resistance. This may also indicate that biochemical tests are unable to correlate fully with phenotypic resistance or serve as a reliable indicator of metabolic resistance.

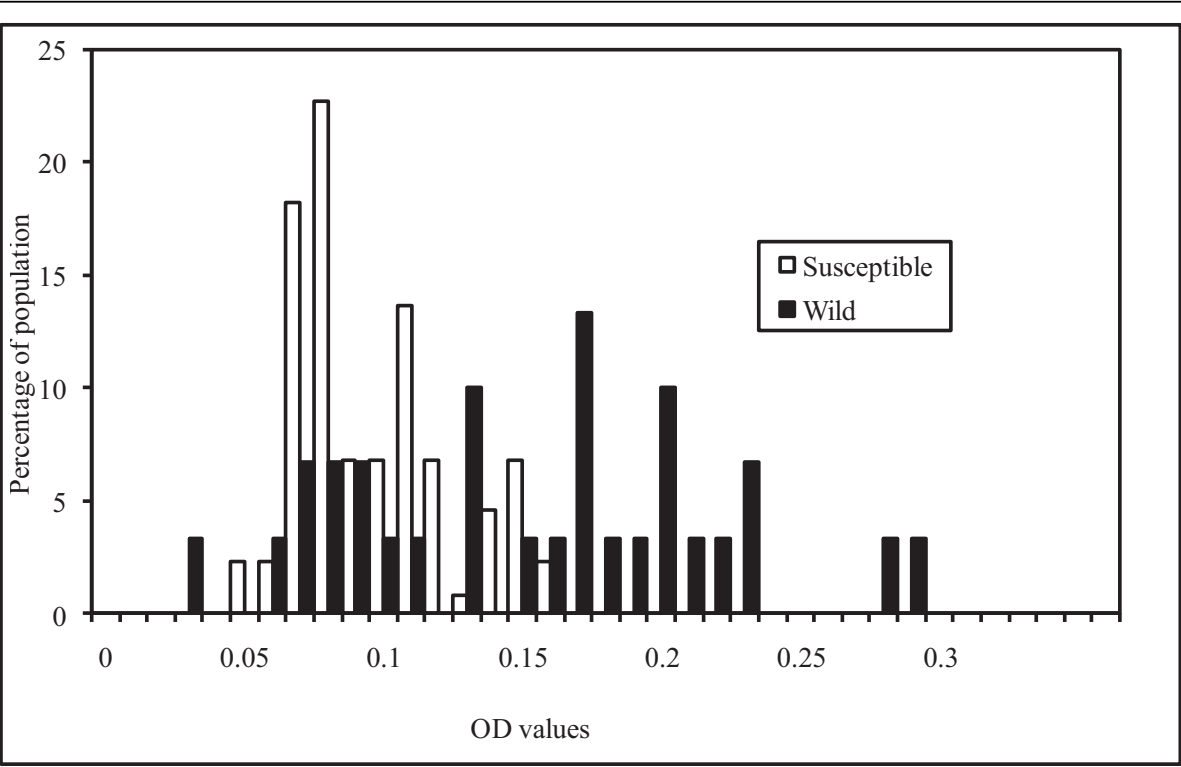

Figure 3 The distribution of activity of mixed function oxidases in wild and susceptible Anopheles arabiensis adult females. Absorbance values recorded at $630 \mathrm{~nm}$. 


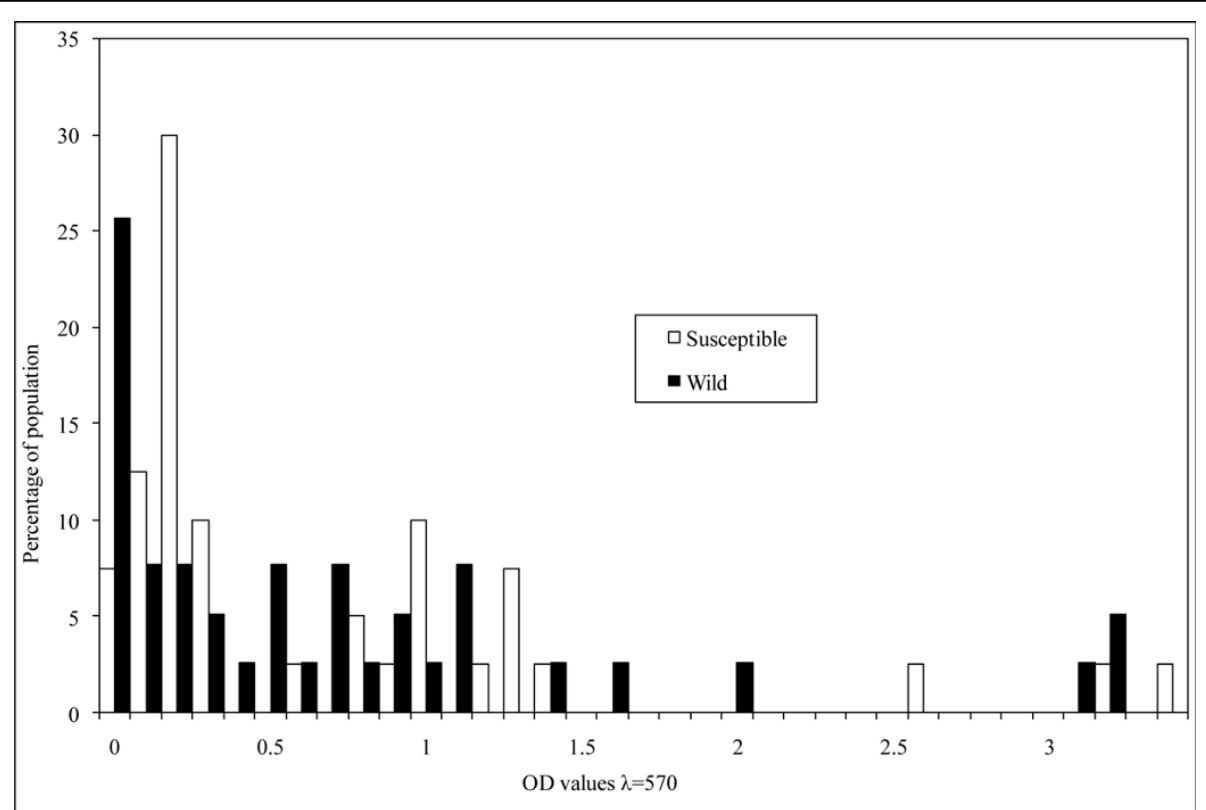

Figure 4 The distribution of activity of $\alpha$-esterases in wild and susceptible Anopheles arabiensis adult females. Absorbance values recorded at $570 \mathrm{~nm}$.

\section{Conclusion}

$\beta$-esterase mediated hydrolysis and oxidative detoxification by monooxygenases are the predominant mechanisms of permethrin resistance in adult An. arabiensis of Lower Moshi, north-eastern Tanzania. The low frequency of phenotypic resistance is probably due to the use of insecticides in rice plantations or use of permethrin-treated nets. At the present level of resistance $(0.16 \%$ allele frequency for L104F $k d r$ genotype), permethrin-treated nets remain efficacious, but the further selection of metabolic and $k d r$ mechanisms, also present in the study area, may in combination prove a graver

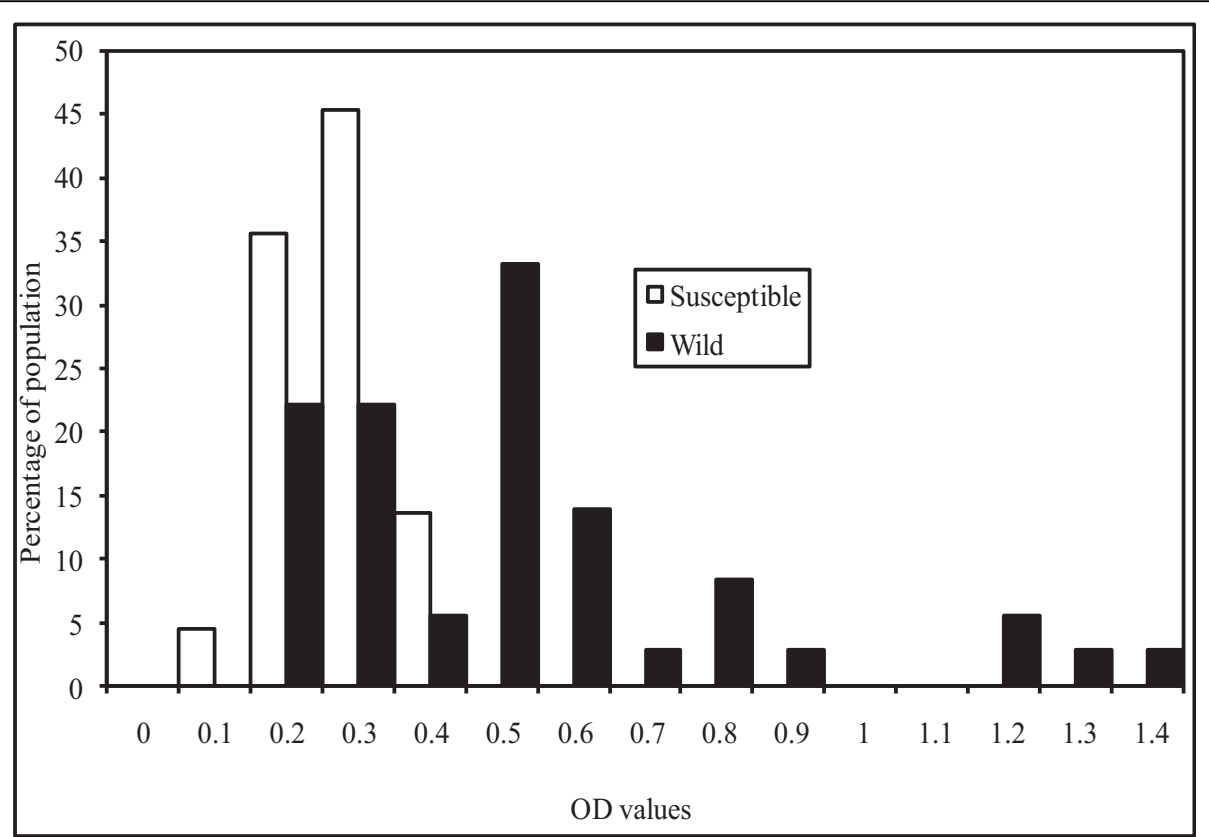

Figure 5 The distribution of activity of $\beta$-esterases in wild and susceptible Anopheles arabiensis adult females. Absorbance values recorded at $570 \mathrm{~nm}$. 
threat. There may be scope for effective use of LLINs that incorporate PBO in the fibres. Resistance was associated with elevated esterases and MFOs but chemical assays that detect elevated levels in individual insects did not necessarily correlate with phenotypic resistance as detected by WHO resistance test kits or CDC bottle bioassays.

\section{Acknowledgements}

We received financial support from Gates Malaria Partnership through the London School of Hygiene and Tropical Medicine and also from the Belgian Technical Cooperation through the Kilimanjaro Christian Medical College, Tumaini University. The assistance from of the villagers from which mosquitoes were collected is highly appreciated. We greatly appreciate the contribution of Mr. Charles Massenga at KCMC Field station, Mabogini Lower Moshi for guidance during fieldwork; Mr. Augustine Mtui, Honest Temba, and James Puya for their support in collecting wild mosquito specimens; Rajabu Mndeme, Emmanuel Mwambungu, Atukuzwe Sanga and Rashid Athumani for insectary support.

\section{Author details}

${ }^{1}$ Pan-African Malaria Vector Research Consortium www.pamverc.org. ${ }^{2} \mathrm{KCM}$ College of Tumaini University, P.O.Box 2240, Moshi, Tanzania. ${ }^{3}$ Department of Biology, University of Ottawa, 30 Marie Curie, Ottawa, ON, KIN 6N5, Canada. ${ }^{4}$ London School of Hygiene and Tropical Medicine, Keppel Street, London WC1E 7HT, UK. ${ }^{5}$ National Institute for Medical Research, Amani Medical Research Centre, P.O. Box 81, Muheza, Tanzania.

\section{Authors' contributions}

Johnson Matowo developed the study design, performed bottle and microplate assays, carried out data analysis and interpretation and wrote the first drafts of the manuscript. Manisha Kulkarni contributed to study design, provided technical help, training and support on biochemical techniques, and revised the manuscript. Mark Rowland obtained funding for the work, interpreted the results and substantially revised the manuscript. Filemoni Tenu, Jovin Kitau and Richard Oxborough participated in data processing, statistical analysis and interpretation. Franklin Mosha co-designed the study and provided critical review of the manuscript. All authors have read and approved the final manuscript.

\section{Competing interests}

The authors declare that they have no competing interests.

Received: 18 January 2010 Accepted: 7 July 2010 Published: 7 July 2010

\section{References}

1. World Health Organization: Vector Control for malaria and other vectorborne diseases. Report of a WHO study group. Geneva, Switzerland: World Health Organization 1995.

2. Chandre F, Darriet F, Manga L, Akogbeto M, Faye O, Mouchet J, Guillet P: Status of pyrethroid resistance in Anopheles gambiae sensu lato. Bull World Health Organ 1999, 77:230-234.

3. Hargreaves K, Koekemoer LL, Brooke BD, Hunt RH, Mthembu J, Coetzee M: Anopheles funestus resistant to pyrethroid insecticides in South Africa. Med Vet Entomol 2000, 14:181-189.

4. Brooke BD, Hunt RH, Koekemoer LL, Doussou-Yovo J, Coetzee M: Evaluation of PCR assay for detection of pyrethroid insecticide resistance in the malaria vector species of the Anopheles gambiae complex (Diptera: Culicidae). J Am Mosa Control Assoc 1999, 15:565-568.

5. Diabate A, Baldet T, Chandre F, Akogbeto M, Guiguemde TR, Darriet F, Brengues $C$, Guillet $P$, Hemingway J, Small GH, Hougard JM: The role of agricultural use of insecticides in resistance to pyrethroids in Anopheles gambiae s.l in Burkina Faso. Am J Trop Med Hyg 2002, 67:617-622.

6. Akogbeto M, Yakoubou S: [Resistance of malaria vectors to pyrethrins used for impregnating mosquito nets in Benin, West Africa](in French). Bull Soc Pathol Exot 1999, 92:123-130.

7. Henry MC, Assi SB, Rogier C, Yovo DJ, Chandre F, Guillet P, Carnevale P: Protective efficacy of lambda-cyhalothrin treated nets in Anopheles gambiae pyrethroid resistance areas of Cote d'lvoire. Am J Trop Med Hyg 2005, 73:859-864.

8. Vulule JM, Beach RF, Atieli FK, Mount DL, Roberts JM, Mwangi RW: Reduced susceptibility of Anopheles gambiae to permethrin associated with the use of permethrin impregnated bed nets and curtains in Kenya. Med Vet Entomol 1994, 8:71-75.

9. Czeher C, Labbo R, Arzika I, Duchemin JB: Evidence of increasing Leu-Phe knockdown resistance mutation in Anopheles gambiae from Niger following a nationwide long-lasting insecticide-treated nets implementation. Malar J 2008, 7:189.

10. World Health Organization: Scaling-up insecticide treated netting programmes in Africa: A strategic framework for coordinated national action. WHO/CDS/RBM/2002.43 Geneva, World Health Organization 2005.

11. World Health Organization: Indoor residual spraying. Use of indoor residual spraying for scaling up global malaria control and elimination. WHO/HTM/MAL/2006.1112 Geneva, World Health Organization 2006.

12. Hemingway J, Hawkes NJ, McCarroll L, Ranson H: The molecular basis of insecticide resistance in mosquitoes. Insect Biochem Mol Biol 2004, 34:653-665.

13. Sonderland DM, Knippe DC: The molecular biology of knockdown resistance to pyrethroid insecticides. Insect Biochem Mol Biol 2003, 33:563-577.

14. Martinez-Torres D, Chandre F, Williamson MS, Darriet F, Berge JB, Devonshire AL, Guillet P, Pasteur N, Pauron D: Molecular characterization of pyrethroid knockdown resistance $(k d r)$ in the major malaria vector Anopheles gambiae s.s. Insect Mol Biol 1998, 7:179-184.

15. Ranson $\mathrm{H}$, Jenson B, Vulule JM, Wang X, Hemingway J, Collins FH: Identification of a novel mutation in the voltage-gated sodium channel gene of Anopheles gambiae associated with resistance to pyrethroid insecticides. Insect Mol Biol 2000, 9:491-498.

16. Martinez-Torres D, Chevillon C, Brun-Barale A, Berge JB, Pasteur Nand Pauron D: Voltage-dependent $\mathrm{Na}+$ channels in pyrethroid-resistant Culex pipiens L mosquitoes. Pesticide Science 1999, 55:1012-1020.

17. Diabate A, Brengues C, Baldet T, Dabire KR, Hougard JM, Akogbeto M, Kengne P, Simard F, Guillet P, Hemingway J, Chandre F: The spread of LeuPhe kdr mutation through Anopheles gambiae complex in Burkina Faso: genetic introgression and de novo phenomena. Trop Med Int Health 2004, 9:1267-1273.

18. Vulule JM, Beach RF, Atieli FK, MCAllister JC, Brogdon WG, Roberts JM, Mwangi RW, Hawley WA: Elevated oxidase and esterase levels associated with permethrin tolerance in Anopheles gambiae from Kenyan Villages using permethrin impregnated nets. Med Vet Entomol 1999, 13:239-244.

19. Kulkarni MA, Rowland M, Alifrangis M, Mosha FW, Matowo J, Malima R, Justin P, Kweka E, Lyimo I, Magesa S, Salanti A, Rau ME, Drakeley C: Occurrence of Leucine to phenylalanine knockdown resistance ( $k d r)$ mutation in Anopheles Arabiensis populations Tanzania detected by a high throughput SSOP-ELISA method. Malar J 2006, 5:56.

20. Verhaeghen K, Bortel WW, Roelants P, Backeljau T, Coosemans M: Detection of the East and West African kdr mutation in Anopheles gambiae and Anopheles arabiensis from Uganda using a new assay based on FRET/ Melt Curve analysis. Malar J 2006, 5:16.

21. World Health Organization: Test procedures for insecticide resistance monitoring in malaria vectors, bio-efficacy and persistence of insecticides on treated surfaces. Geneva, Switzerland, World Health Organization 1998.

22. Privora M: Use of KT50 for orientative evaluation (screening) of sensitivity of lies to insecticides. Journal of Hygiene, Epidemiology, Microbiology and Immunology 1975, 9:184-194.

23. Brogdon WG, MCAllister JC: Simplification of adult Mosquito Bioassays through use of time-mortality determinations in glass bottles. J Am Mosa Control Assoc 1998, 14:159-164.

24. Brogdon WC, MCAllister JC: Insecticide Resistance and Vector Control. Emerg Infect Dis 1998, 4:605-613.

25. Brogdon WG: Biochemical resistance detection: an alternative to bioassay. Parasitol Today 1989, 5:56-60.

26. Brogdon WG, MCAllister JC, Vulule JM: Association of heme peroxidase activity measured in single-mosquitoes identifies individuals expressing an elevated oxidase for insecticide resistance. J Am Mosa Control Assoc 1997, 13:233-337. 
27. ljumba JN, Mosha FW, Lindsay SW: Malaria transmission risk variation derived from different agricultural practices in an irrigated area of northern Tanzania. Med Vet Entomol 2002, 16:28-38.

28. Kulkarni MA: Monitoring pyrethroid susceptibility in Anopheles arabiensis in relation to agricultural insecticide use in the Kilimanjaro Region of Tanzania. PhD Thesis McGill University, Montreal, Canada 2006, 57-73.

29. World Health Organization: Instructions for determining the susceptibility or resistance of adult mosquitoes to organochlorine, organophosphate, and carbamate insecticide-diagnostic test. WHONBC/81.806 Geneva, World Health Organization 1981, 6.

30. Abbott WS: A method of computing the effectiveness of an insecticide. J Economic Entomol 1925, 18:265-267.

31. Vulule JM, Beach RF, Atieli FK, Mount DL, Roberts JM, Mwangi RW: Longterm use of permethrin-impregnated nets does not increase Anopheles gambiae permethrin tolerance. Med Vet Entomol 1996, 10:71-79.

32. Mosha FW, Lyimo IN, Oxborough RM, Matowo J, Malima R, Feston E, Mndeme R, Tenu F, Kulkarni M, Maxwell CA, Magesa SM, Rowland MW: Comparative efficacies of permethrin- deltamethrin- and alphacypermethrin-treated nets, against Anopheles arabiensis and Culex quinquefasciatus in northern Tanzania. Ann Trop Med Parasitol 2008, 102:367-376

33. Stump AD, Atieli FK, Vulule JM, Besansky NJ: Dynamics of pyrethroid knockdown resistance allele in western Kenyan populations of Anopheles gambiae in response to insecticide-treated bed net trials. Am J Trop Med Hyg 2004, 70:591-596.

34. Miller TM: Mechanisms of resistance to pyrethroid insecticides. Parasitol Today 1988, 4:S8-S12.

35. Zebra E: Insecticidal activity of pyrethroids on insects of medical importance. Parasitol Today 1993, 4:S3-S7.

36. Ishaaya I: Insect detoxifying enzymes: Their importance Pesticide synergism and resistance. Arch Insect Biochem Physiol 1993, 22:263-276.

37. Sun YP, Johnson ER: Quasi-synergism and penetration of insecticides. J Econ Entomol 1972, 65:349-353.

38. Kennaugh L, Pearce D, Daly JC, Hobbs AA: A piperonyl butoxide synergizable resistance to permethrin in Helicoverpa armigera which is not due to increased detoxification by cytochrome P450. Pestic Biochem Physiol 1993, 45:234-241.

39. Gunning RV, Devonshire AL, Moores GD: Metabolism of esfenvalerate by pyrethroid-susceptible and -resistant Australian Helicoverpa armigera (Lepidoptera: Noctuidae). Pestic Biochem Physiol 1995, 51:205-213.

40. Khot AC, Bingham G, Field LM, Moores GD: A novel assay reveals the blockade of esterases by piperonyl butoxide. Pest Manag Sci 2008, 64:1139-42.

41. Chareonviriyaphap $T$, Rongnuparut $P$, Chantarumporn $P$, Bangs MJ: Biochemical detection of pyrethroid resistance mechanisms in Anopheles minimus in Thailand. J Vector Ecol 2003, 28:108-116.

doi:10.1186/1475-2875-9-193

Cite this article as: Matowo et al:: Biochemical basis of permethrin resistance in Anopheles arabiensis from Lower Moshi, north-eastern Tanzania. Malaria Journal 2010 9:193.

\section{Submit your next manuscript to BioMed Central and take full advantage of:}

- Convenient online submission

- Thorough peer review

- No space constraints or color figure charges

- Immediate publication on acceptance

- Inclusion in PubMed, CAS, Scopus and Google Scholar

- Research which is freely available for redistribution

Submit your manuscript at www.biomedcentral.com/submit
Biomed Central 